\title{
Computer supported collaborative learning in problem-based learning of statistics
}

\begin{abstract}
This study investigated computer supported collaborative learning in the Web-based learning environment designed using the constructivist Problem-Based Learning (PBL) approach. One group of students was exposed to the constructivist PBL Web-based learning whilst another group was exposed to traditional PBL learning approach. A lecture-based teaching was given to another group. Thus, a quasi-experimental non-equivalent post-tests research design was adopted. The analysis of the data revealed that the web-based PBL learning and the traditional PBL yielded positive educational output and highlighted the importance of the scaffolding by the use of guided questions in the learning processes that supported both better understanding and motivation in the learning of statistics. Highly positive responses were recorded from the respondents in their evaluation of learning performances, hence indicating the strength of both the web-based and traditional PBL approach in the enhancement of learning effectiveness and motivation towards learning.
\end{abstract}

Keyword: Problem-based learning; Computer supported learning; Statistics performance; Instructional efficiency 